\title{
Investing in quality childhood: beyond survival
}

\author{
Deepika Attygalle \\ President, College of Community Physicians of Sri Lanka, 2015/16 \\ Correspondence: erangi@outlook.com \\ DOI: http://doi.org/10.4038/jccpsl.v23i1.8109 \\ "We owe our children, the most vulnerable citizens in our society, a life free of violence and fear." \\ - Nelson Mandela, Former President of South Africa
}

Sri Lanka's remarkable progress in improving the population's health status over the past several decades is internationally acknowledged. Increased life expectancy at birth (from 40 years in 1930 to 65 years in 1970 and 72 years since 1990), and the decline in both infant mortality (15 deaths per 1000 live births in 2006) and total fertility (from 4.7 births per woman in 1970 to 2.3 in 2006) have been achieved largely through the effective public health services covering almost the entire population, including the former conflict-affected areas.

As the country has achieved high coverage of all health indices, it is timely that we focus our attention not merely on the high survival rates but also on ensuring that all our children have an equal chance to enjoy quality survival; thrive in a safe and protective environment, and achieve their maximum potential. Time has come for all of us to examine what we know and what we need to know to achieve this goal for our children - the children of the nation.

Etymologically, the term 'child' comes from the Latin word infants, which means 'the one who does not speak'. In feudal era, children were considered 'small adults' and were often employed in different work settings. The idea that children needed special protection arose only around the mid-19th century in France. In 1841, laws protecting children in their workplaces came into being in Europe. This notion evolved through many centuries and in 1989, the UN Convention on the Rights of the Child (CRC) defined the term 'child' more precisely as 'any human being below the age of eighteen years, unless under the law applicable to the child, majority is attained earlier'. Sri Lanka ratifies the CRC and considers 'a person under 18 years of age' as a child (1).
The concept of a child is very wide and varies between cultures and countries, and now a person from birth until adulthood is recognised as a child. Often, even within a country, a number of different laws may specify the age limits in different legal circumstances such as in Sri Lanka, child labour at 14 years, age of consent at 16 years; age of marriage and age of criminal responsibilities at 18 years. What characterizes a child is his/her youth and vulnerability, one who has no means of protecting him/herself, and one who has to be the object of specific protection (1).

CRC adopted by the United Nations has become the most widely ratified human rights treaty in history. To date, almost every nation in the world has ratified it and is committed to promote the rights specified therein. Historically, in 1939, Sri Lanka through the Child and Young People Ordinance recognized that children should be treated differently from adults and in a more accommodative manner by the legal system. Sri Lanka ratified the CRC on 12 July 1991.

Global deliberations on children are reflected in many ways through a multitude of lenses. The most recently endorsed sustainable development goals (SDGs) have 17 interlinked goals with 169 targets, and more than half of these are either highly relevant or somewhat relevant to children. In addition, the every new-born action plan presented at the World Health Assembly in 2014 focuses on babies and children, highlighting their right to thrive and reach their full social and economic potential.

Realization of Child Rights Index (RCRI) is another reflection of the willingness to have a comprehensive and holistic view of children's rights and wellbeing. Although this, like any other index has its own limitations, 
it is useful in providing an overall picture of the status of children in the world. RCRI for Sri Lanka is $7.59 / 10$, and we hold the 92nd rank among 196 nations. It is noteworthy that the Maldives with a RCRI of 7.7 is ranked above us (2).

Globally, over 200 million children under 5 years of age face multiple deprivations. Although global child mortality trends are on the decrease, half of the children live in extreme poverty (3). One in every 6 children around the world is engaged in child labour (4). An estimated 2 million children worldwide are exploited through prostitution or pornography each year (5). More than 300,000 children around the world are actively participating in armed conflicts. Approximately 25 million children and adolescents are uprooted from their home (6). They make up nearly half of the refugee population worldwide and 150 million children living in streets, of whom $40 \%$ are homeless, an unprecedented number in history (7).

In Sri Lanka, children under 5 years constitute 8.3\% of the population and the adolescents about $19 \%$. Almost $99 \%$ of mothers come to hospitals for their deliveries and approximately 3,500,000 babies are born per year, of whom 95\% receive care by public health midwife (PHM) at the community level, and 92\% enrolled in preschools and $94 \%$ in primary schools, while the under 5 mortality is as low as 9 per 10,000 live births (8). However, one fourth of our children or every fourth child lives in poverty $(9,10)$. Around 15,000 children live on the street (11) while $10 \%$ of under 16 year deaths are due to injuries, nearly 100,000 children are engaged in child labour and nearly 63,000 (12) in hazardous occupations, of whom nearly half work for a salary of Rs. 2000 per month. On the other hand, $80 \%$ of these children attend school while being engaged in economically active work (13).

It is reported that every day, on the average, 3 children are being abused. It is reported that on the average, 350 children with maltreatment are referred every year to the Colombo JMO's office from the catchment area of Colombo (14). Over 1500 cases of violence against children are reported every year to the National Child Protection Authority. Close to one third of cases in high courts are related to a child victim.

Routine data supported by research have shown that there is an increasing trend of juveniles being involved in antisocial activities. Juvenile offences or crimes are anti-social behaviour of children and adolescents that the society does not approve of, and for which the punishment or corrective measures are justified in the public interest. It is reported that there are 500 children at any given time living in institutions, remand homes, rehabilitation centres or correction centres, and in prison.

Most often violence and crimes lead to imprisonment. Although the prison population reflects only the tip of the iceberg, it is worth exploring the nature of these citizens. According to prison statistics in 2013, there are around 30,000 convicted prisoners at present. It is important to note that $53 \%$ of them have had readmissions. Most of their first admission had been during their adolescence and youth. Further, $75 \%$ of the prisoners have had their education above Grade 8 and nearly 30\% above the standard of GCE (Ordinary Level) (15).

Sri Lanka adopts a separate judicial process for juvenile crimes and also adopts distinct methods of punishment, which focus on rehabilitation and reintegration of offenders into the society as law abiding persons. However, the existing correctional methods, especially the institutional rehabilitation methods have various problems and weaknesses that warrant reconsideration.

According to prison statistics, among the children in legal custody, many had been brought up by their parents, and educated only up to Grade 8 (15). All these children had been denied of the opportunity to realize their right to develop to their full potential. One may argue that the numbers are small. Every child counts and therefore, we cannot neglect these numbers. Further research is needed to explore the depth of this problem.

In exploring the depth of the problem, it is important to ask the question "Why does this happen?", "Why are they on the street?", "Why are they being abused?”, "Why are they in receiving homes?", "Why do they become offenders?” etc. There is a large body of research in these areas, and the key contributory factors are reported as lack of adequate family support, foreign employment of the mother, separation or divorce of parents, domestic violence, abusive behaviour of parents and extreme poverty. Drug and alcohol addiction, smoking and gambling of fathers are well-known to drive children, especially the adolescents to seek satisfaction outside the home, where they ultimately end up in antisocial 
activities. It is well documented that in a motherless home environment, many children could easily get involved in such behaviour. Absence of a loving home environment and distant parents may drive children to be manipulative. Sometimes, young people are driven to antisocial acts for fun and excitement (16).

There is anecdotal evidence on the rapidly changing patterns of modern living making it difficult for children and adolescents to adjust themselves to new ways of life. Temptation for modern luxuries, exposure to sex and violence in movies, DVD etc., misuse of technology such as mobile phones and internet without adequate parental controls are some factors that may prompt young people to commit crimes.

Social determinants of violence place special emphasis on the primary caring and protective responsibilities of the family and community. There are many studies that show significant associations between antisocial behaviour and adverse childhood experiences such as childhood abuse and neglect - growing up with domestic violence, substance abuse or mental illness in the home, parental discord and crimes. Adverse childhood experience was also associated significantly with interpersonal and self-directed violence (17).

Research has shown that offenders who were in prison due to sexual abuse had a history of being a victim of sexual abuse. Present evidence shows that it is the interaction between genes and the environment that predicts criminal behaviour; having a genetic predisposition for criminal behaviour does not determine the actions of an individual, but if exposed to the right environment, then chances are greater for engaging in criminal or anti-social behaviour (18). It has been shown that adverse childhood experiences - smoking, alcohol abuse, illicit drug abuse, sexual behaviour, mental health, risk of victimization, stability of relationships, homelessness have a strong influence on adolescent health, reproductive health and performance in the workforce (19). Thus, it is evident that adverse childhood experience is a leading determinant of health and social wellbeing of a nation. How can we then minimize adverse childhood experiences? It is worth conceptualizing this through a preventive model that includes primordial, primary, secondary and tertiary levels of prevention.

Primordial prevention would play a key role in preventing adverse childhood experience (ACEs), which involves planning strategies to reduce the antecedent causes before it happens and minimizing the risks for violence that exist in communities and population groups. Further, primary, secondary and tertiary prevention could be categorized as strengthening crisis response mechanisms immediately after violence, long term response after violence has occurred for the victim (to reduce the negative effects) and for the offender (to prevent further violence), strengthening the school of youthful offenders, certified schools and remand homes for children, and post event follow up to prevent further violence, respectively. It is observed that we heavily invest in primary and secondary aspects of the model while primordial and tertiary prevention needs further strengthening. This highlights the importance of investing in early childhood care and development (ECCD) as the returns are more. Early childhood is an extremely sensitive period in human development, during which the brain, especially the circuitry governing emotion, attention, self-control and stress, is shaped by the interplay of the child's genes and experiences. As children grow, the biological and environmental factors that determine their development become increasingly intertwined. When the environment is a secure and a positive one, these factors join forces to help maximize an individual's potential. However, when children face enduring obstacles to healthy development such as poverty, inappropriate care or violence, the environment and biology may route them on a course to emotional, physical and mental health problems.

It is the complex interplay between nature and nurture that lays the foundation for sound healthy development. Brain increases its connectives in early childhood. Every touch, every movement in a child's life is translated into electrical and chemical activity in the brain. Billions of cells organize into networking, trillions of synapses are made. The physical, social-emotional cognitive and language capacities of a child are gradually developed over a period spanning from conception to 8 years of age. These capacities help child to think, solve problems, communicate, express their emotions and form relationships, which are the building blocks for future human capital formation. Thus, ECCD becomes the essential foundation for achieving the full developmental potential and results for children. Early stimulation and interaction with care givers jumpstart the journey of a lifetime of learning, beginning with a strong foundation in early learning. Creating the right conditions for early childhood development is likely to be more effective and less costly than addressing problems at a later stage, even in preventing violence. 
There is ample evidence suggesting that high-quality early childhood programs lay the foundation for success in schooling and positively impact on development. What we do not seem to recognize is the fact that at present our attention is focused mainly on issues that represent the "downstream" - the wreckage caused by child abuse, neglect and other adverse childhood experiences. According to the Economist James Heckman, a Nobel laureate, investment in the early years of life before the formal school system gives the greatest return on competence and coping skills. Given this knowledge and the need for an innovative knowledge based economy, it is clear that we need to invest in early years if we are to have higher quality population. If we are to think on a purely economic basis, it makes a lot of sense to invest in the young. "Early learning produces later learning and early success breeds later success.” Therefore, it is imperative that we, as a nation recognize the importance of the early years of childhood for a quality life and that be regarded as a national responsibility and priority to support families and parents to ensure a quality childhood for their children.

Wellbeing of children is intimately linked to the wellbeing of their family and community. It is no longer a matter of child health and survival; rather, the focus has been significantly broadened to include the overall wellbeing of the child, family and the community. Thus, for a child to maximize his/her potential, for he/she, there should be a family that is ready to support his/her development, a school that is ready to welcome him/her to advance his/her development, and a community that understands its commitment towards a developing child and his/her early years. Therefore, special emphasis needs to be given to children living in socially adverse environments where the most vulnerable live, and circumstances where mothers are more likely to be the poorest, most undernourished, depressed, mentally vulnerable and less responsive to their children's needs. It is encouraging to note that according to national statistics, the government of Sri Lanka spends 8-10\% of its total national expenditure and 6-7\% of the gross domestic product on children, which is commendable although there is scope for improvement.

Notably, education and health expenditure constitutes the bulk of the investments in children at both national and provincial levels while the share of ECCD, child protection and participation is minuscule. This is the major challenge that needs urgent attention. Investments in government owned pre-school structures with skilled human resources have shown the greatest impact on early childhood development in the developed world. According to the study carried out by Save the Children on child budgeting in 2015, the government of Sri Lanka spends on an average Rs.96 per child per month, despite having a vast geographical variation. Investment in education and health gets the highest proportion than investment in early childhood, child participation and protection. Regardless of various strategies requiring further resourcing, ensuring the quality of fund utilization and efficiency in resource management also remains a significant challenge that warrants immediate attention.

Responsible investments in services for young children and their families focus on benefits relative to cost. Inexpensive interventions that do not meet quality standards are a waste of money. Stated simply, sound policies seek maximum value rather than minimal cost. Implementing a multi-sectoral approach, good governance, coordination and ensuring child centred investments/budgeting, and accountability in the systems are some of the fundamentals in achieving this success. It should be noted that safety and security do not just happen - it is a result of collective consensus and public investment.

\section{References}

1. National Child Protection Authority Act. Stat. 50, 1998.

2. Humanium Organization. Realization of Children's Rights Index. Geneva, 2008. Available from: http://www.humanium.org/en/rcri/.

3. Olinto P, Beegle K, Sobrado C, Uematsu H. The state of the poor: Where are the poor, where is extreme poverty harder to end, and what is the current profile of the World's poor? World Bank - Economic Premise 2013; 125(2).

4. UNICEF. Child labour 2015. Available from: http://www.unicef.org/protection/57929_child_labour.html.

5. ECPAT. Testimony before the Senate foreign relations subcommittee on near Eastern and South Asian affairs 2002. Available from: http://www.ecpatusa.org/pdf/senate_testimony.pdf.

6. Child soldiers global report, 2008.

7. Patt M. Street children: the prevalence, abuse \& exploitation of street children. Available from: http://gvnet.com/streetchildren/00-StreetChildren.htm.

8. Family Health Bureau. Annual Report on Family Health - 2013. Colombo: Ministry of Health, 2014.

9. Centre for Poverty Analysis. Child poverty in Sri Lanka. Christian Children’s Fund Sri Lanka, 2008. 
10. Remnant F, Cader AA, Coull J. Child poverty in Sri Lanka. CEPA Briefing Paper Series: Christian Children's Fund, 2008.

11. Senaratna BCV, Wijewardana BVN. Street children in Colombo: what brings them to and sustains them on the streets? Sri Lanka Journal of Child Health 2013; 42(2).

12. Family Health Bureau \& Expert Committee on Ergonomics. Child Injuries in Sri Lanka. Colombo: Family Health Bureau \& Sri Lanka Medical Association, 2015.

13. Department of census and statistics, Ministry of Finance and Planning. Child Activity Survey 2008/09. Colombo: Ministry of Finance and Planning, 2011.

14. Judicial Medical Officer. Statistics. 2016.

15. Department of Prisons. Prisons statistics of Sri Lanka. Prisons Headquarters, 2014.
16. WHO. World report on violence and health; Summary. Geneva: World Health Organization, 2002.

17. Duke NN, Pettingell SL, McMorris BJ, Borowsky IW. Adolescent violence perpetration: associations with multiple types of adverse childhood experiences. Pediatrics 2010; 125(4).

18. Reavis JA, Looman J, Franco KA, Rojas B. Adverse childhood experiences and adult criminality: how long must we live before we possess our own lives? Permanente Journal 2013; 17(2): 4.

19. WHO. ECD+ workshop preceding the WHO's 6th milestones in the global campaign for violence prevention meeting. Mexico City: UBS optimus Foundation, World Health Organization, 2013. 